\title{
An Improved Laying Technique for Ceramic Floor Tiling
}

\author{
D. A. R. Dolage \\ Department of Civil Engineering, Open University of Sri Lanka
}

\begin{abstract}
There are 3 different versions of tile laying techniques adopted in the industry at present and no attempt has been made so far to evaluate these techniques and thereby to promote the most desirable technique. Of the three techniques, in the first two, tiles are fixed on to the already hardened bed using cement slurry. These two techniques differ from one another because one uses a rectangular shaped toothed trowel while the other uses the standard mason's trowel to apply the cement slurry. In the case of the third technique, tiles are fixed on to fresh mortar bed after applying a coating of lean cement slurry. Data was collected from 15 sites; five for each technique to determine the cost effectiveness of each technique. Out of the above, 12 sites were considered to evaluate the performance of each technique with respect to quality.
\end{abstract}

The results obtained after the analysis revealed that the third technique which involves fixing of tiles soon after the mortar bed is laid, is the most cost effective since it consumes less cement and sand. The quality of tile laying was assessed in terms of two parameters namely, bondage and level. The above technique is the best with respect to bondage of tiles with the substrate. However, this technique performs poorly when it comes to maintaining the uniformity of levels of individual tiles. This is due to the deformability of fresh mortar bed on which tiles are placed. The tilers who applied this new technique were not entirely conversant with it. Therefore, the results obtained could be further improved by engaging tilers skilled in this technique.

If the public and private sector stakeholders' sponsorship is forthcoming this technique can be promoted and personnel to be engaged can be trained so that it can be applied on a mass scale.

\section{Introduction}

There are several floor finishing systems used in Sri Lanka; Cement Rendering, Terrazzo Flooring, Floor Tiling, Granite Flooring and Parquet Flooring, to name some. Of these, tiled floors are popular due to their durability, surface finish and economy. Even though there are two main kinds of floor tiles used; clay tiles and ceramic tiles, this study is only focussed on ceramic floor tiling, as its use is widespread. For different reasons such as low price, durability, easy maintenance, good aesthetic appearance, availability in a wide range etc., ceramic tiled floors have become popular over the last two decades. As a result,

Manuscript received: 24.09.2004

Revised manuscript received: 29.04.2005

Manuscript accepted: 02.05.2005 ceramic floor tiling has become a specialised trade thereby creating a trend where more and more masons are converting themselves into tilers.

There are different ceramic tile laying techniques used in our country of which two are almost equally popular and the third method is sparsely adopted and the main focus of this study is to investigate the efficacy of this technique. These techniques differ from one another in terms of usage of material and labour, finished quality, speed of construction and the cost. The two similar techniques referred to above are traditional and userfriendly and so tradesmen skilled in these techniques are abundant.

At present, designers' and/or clients' choice of the flooring type to be used for their project 
depends on the level of aesthetic appearance required, purpose of the building and the cost. It is common knowledge that ceramic tiling is proposed for most of the buildings at present. However, at no project does the Engineer specify the particular type of technique to be adopted for ceramic tiling. It is the contractor who finally decides on the technique at the site. Tilers hardly deviate from traditional methods towards labour and material conserving versions proving the notion that innovativeness of our skilled workers is still at a low level. Moreover, at present the construction industry is faced with a crisis situation owing to the scarcity of material and escalating prices. Therefore, innovation and development of cost saving and quality enhancing techniques should be the order of the day. Therefore, national Institutes and personnel concerned with these objectives should endeavour to prove systematically the viability of such innovations and, thereafter, facilitate these mainly through training of personnel engaged in the art of tiling and to ensure the sustainability. No research has been published locally pertaining to ceramic tile laying let alone on the determination of a cost effective laying technique.

\section{Objectives}

The research study was aimed at the following objectives:

- To determine the time taken to lay a unit area of tiling under each technique.

- To determine the cost incurred in laying a unit area of tiling under each technique.

- To compare the variance of quality parameters under each technique.

- To ascertain the best tile laying technique with respect to different parameters namely cost, quality, and time.

\section{Research Methodology}

The initial survey carried out revealed that there are two widely used tile laying techniques in the construction industry and these two differ marginally from one another with respect to different parameters. The third technique is not so known but looked promising as an improved technique. Observations were made at five different construction sites for each technique. Firstly, observations were made in terms of material consumption and time taken to lay tiles in a unit area. Secondly, observations were made to determine the extent of improperly bonded tiles and the extent of tiles that have significant vertical level divergences. These data were presented in tabular form for easy comparison.

Thereafter, the cost incurred in laying a floor area of one square was determined under each technique. The number of sites considered for quality assessment had to be restricted to four since some of the premises of which floors were used for the first part of the study had already been moved in and were not available for measurement. To ascertain which of the three tile laying techniques produced the besttiled floor following three methods were employed for each technique;

- Each tile laid was tapped with an extendable steel rod with a steel ball fitted at the end. The tiles were tapped with the end to which the ball has been fitted. The kind of sound generated indicates the degree of bondage

- Measurements in both $\mathrm{X}$ and $\mathrm{Y}$ directions were taken with respect to a string pulled along the edges of the two end tiles of each tile line in both $\mathrm{X}$ and $\mathrm{Y}$ directions to observe the degree of deviation.

- A metal straight edge of length $1.5 \mathrm{~m}$ was used together with gauge strips to measure the relative level difference between tiles. 


\section{Ceramic Tile Laying Techniques}

Irrespective of the technique to be adopted for a particular floor one major consideration for tile laying is having a relatively levelled and firm underlay and the preferred option for this is always a concrete surface. Since this is a common requirement for all the techniques and the scope of the study is the determination of the most effective technique, this study does not dwell on the preparation of the concrete substratum. As mentioned earlier, the initial survey revealed that there are three tile laying techniques adopted in practice and a concise description of these techniques is given below;

\section{Technique I}

- Clean the concrete floor thoroughly and thereafter wet it before the laying of mortar bed

- Place mortar of composition 1:4 (cement: sand) mortar of stiff plastic consistency on already dampened floor.

- Spread and level the mortar evenly and thereafter compact thoroughly to the required thickness. Thickness of the bed normally varies between $12 \mathrm{~mm}-20 \mathrm{~mm}$.

- Allow the bed to dry at least for 24 hours.

- Apply the cement slurry on bedding with a specially made mason's trowel with triangular toothings so that the thickness of cement slurry is even and maintained at $2 \mathrm{~mm}-3 \mathrm{~mm}$.

- Place the tiles gently and thereafter tap them with a rubber mallet or a wooden block to obtain an even and firm surface while ensuring that bondage between the tile and the bed is sound.

\section{Technique 2}

- Clean the concrete floor thoroughly and thereafter wet it before the laying of mortar bed.
- Place mortar of composition 1: 4 (cement: sand) mortar of stiff plastic consistency on already dampened floor.

- Spread and level the mortar bed evenly and thereafter compact the bed thoroughly to the required thickness. Thickness of the bed normally varies between $12 \mathrm{~mm}-20 \mathrm{~mm}$.

- Allow the bed to dry at least for 24 hours.

- Apply the cement slurry on the bedding using a mason' $s$ trowel. In this case the thickness of cement slurry layer cannot be maintained evenly as in the previous technique. Thickness of cement slurry layer varied between $3 \mathrm{~mm}-4 \mathrm{~mm}$.

- Place the tiles gently and thereafter tap them with a rubber mallet or a wooden block to obtain an even and firm surface while ensuring that bondage between the tile and the bed is sound.

\section{Technique 3}

- Clean the concrete floor thoroughly and thereafter wet it before the laying of mortar bed

- Place mortar of composition 1: 4 (cement: sand) mortar of stiff plastic consistency on already dampened floor.

- Spread and level the mortar evenly and thereafter compact thoroughly to the required thickness. Thickness of the bed normally varies between $12 \mathrm{~mm}-20 \mathrm{~mm}$. In this method the extent of mortar bed laid should be limited to an area on which the tiller can fix tiles before the initial setting of cement in mortar commences.

- Spread a thin cement slurry over the wet mortar bed immediately after the compaction.

- Place the tiles gently and thereafter tap them with a rubber mallet or wooden block to obtain an even and firm surface while ensuring that bondage between the tile and the bed is sound. 


\section{Results of the observations and Analysis}

\subsection{Material usage}

Material usage for both bedding and tiling for an area of one square has been calculated for each technique and tabulated as shown in Table 5.1 .

\subsection{Cost Analysis}

The cost analysis is based on the material and labour rates which prevailed during the month of August 2004. In these sites the only tile size used was $300 \mathrm{~mm} \times 300 \mathrm{~mm}$ and it was observed that approximately $1 \mathrm{~kg}$ of tile grout was used for one square of tiling irrespective of the technique used. The volume of one mortar pan is equal to $0.25 \mathrm{cu}$. ft. For the purpose of computing the cost of laying a square of ceramic tiles average values obtained from Table 5.1 was used. The total cost of laying ceramic tiles per square has been computed and shown in Table 5.2.

The cost of material is as shown below;

Cement - Rs. $440 /=$ per $50 \mathrm{~kg}$ bag

Sand - Rs. $4400 /=$ per cube

Tile grout - Rs. 90/= per $1 \mathrm{~kg}$ bag

Labour rates applicable for tilling and bedding are as shown below;.

Tiller (Skilled labour) - Rs.500/= per day (8hrs)

Helper (Unskilled labour) - Rs. 300/= per day (8 hrs)

Table 5.1: Average Material and labour Usage for a Square

\begin{tabular}{|l|c|c|c|c|}
\hline Material/Labour & Site & Technique 1 & Technique II & Technique III \\
\hline Cement & Site I & 2.30 & 2.81 & 1.57 \\
(Bags) & Site II & 1.98 & 3.33 & 1.67 \\
& Site III & 2.30 & 3.63 & 1.45 \\
& Site IV & 2.03 & 3.42 & 1.67 \\
& Site V & 2.06 & 3.15 & 1.33 \\
\hline Average & & 2.13 & 3.25 & 1.54 \\
\hline Sand & Site I & 30.53 & 25.27 & 21.43 \\
(Pans) & Site II & 27.28 & 29.82 & 25 \\
& Site II & 27.62 & 37.21 & 12.85 \\
& Site IV & 25.73 & 31.58 & 20.83 \\
\hline Average & Site V & 26.04 & 29.47 & 20 \\
\hline Tiller & & 27.44 & 30.67 & 20.02 \\
(Hrs) & Site I & 3.29 & 3.43 & 5 \\
& Site II & 2.86 & 4.83 & 6.67 \\
& Site III & 4.55 & 6.28 & 5.03 \\
& Site IV & 4.56 & 7.02 & 4.17 \\
\hline Average & Site V & 3.97 & 4.74 & 4.44 \\
\hline Helper & & 3.85 & 5.26 & 5.06 \\
\hline (Hrs) & Site I & 3.29 & 3.43 & 5 \\
& Site II & 3.81 & 4.83 & 6.67 \\
& Site III & 4.55 & 8.14 & 7.26 \\
\hline Site IV & 4.56 & 7.02 & 4.17 \\
\hline Average & Site V & 3.97 & 4.74 & 4.44 \\
\hline & & 4.04 & 5.63 & 5.51 \\
\hline
\end{tabular}


Table 5.2: Laying Cost Per Square (all values in Rupees)

\begin{tabular}{|l|c|c|c|}
\hline Material/Labour & Technique I & Technique II & Technique III \\
\hline Cement & 938 & 1,430 & 678 \\
\hline Sand & 302 & 338 & 220 \\
\hline Grout & 90 & 90 & 90 \\
\hline Material cost & 1,330 & 1,858 & 988 \\
\hline Tiller & 241 & 329 & 316 \\
\hline Helper & 151 & 211 & 207 \\
\hline Labour cost & 392 & 540 & 523 \\
\hline Total cost & 1,722 & 2,398 & 1,511 \\
\hline
\end{tabular}

\subsection{Quality Comparison}

The most important parameters necessary to differentiate between two tiling sites with respect to quality are as follows;

Bondage between the tiles and the bedding

Shifts in tiles in both $\mathrm{X}$ and $\mathrm{Y}$ direction

Divergence in levels of tiles

\subsubsection{Bondage between tiles}

A steel rod with a ball fitted at one end was used to assess the bondage between tiles and the bedding. When a tile is tapped with the ball, if the bond is not proper the kind of sound generated is hollow. On the contrary if the bond is proper a particular sound is generated that indicates a sound bond. Table 5.3.1 depicts the extent of defective areas at each site for all three techniques.

\subsubsection{Shifts in $X$ and $Y$ direction}

The shifts in tiles in both $\mathrm{X}$ and $\mathrm{Y}$ directions were measured by holding a string pulled tightly along the edges of the two end tiles of each row in each direction. The reason for keeping a groove between tile lines is to accommodate inherent dimensional variations in tiles. However, these grooves also accommodate any shifts in tiles caused due to the deficiencies inherent in the techniques adopted. Therefore, the width of the groove reflects the cumulative effect of both the dimensional variations of tiles and the shifts caused due to deficiencies inherent in the technique adopted. As a result of this it is not easy to separate out the extent of shift influenced by the technique.

\subsubsection{Level Differences}

The vertical level differences of tiles were measured by placing a metal straight edge along the centre of each tile row with respect to the bottom of this edge. The visible level differences were measured by inserting appropriate gauge strips the thickness of which varied from $1 \mathrm{~mm}$ to $3 \mathrm{~mm}$. Initially, a levelling instrument was used for this purpose but had to be abandoned since the level differences were too indiscernible (less than $5 \mathrm{~mm}$ ) to be measured with a levelling instrument. Table 5.3.3 depicts the extent of defective areas due to the divergence in the vertical level associated with all three techniques.

It was observed that the vertical level differences were relatively marginal with respect to Technique $I$ as the tiles are fixed after the bed is completely hardened. Under Technique III, the average vertical divergence is significant. This is so due to two main reasons. Firstly, the increase in compressibility of freshly laid mortar bed when the thickness 
Table 5.3.1:Average Percentage of Defective Area Due to Poor Bondage

\begin{tabular}{|l|l|l|l|l|l|}
\hline & & Site I & Site II & Site III & Site IV \\
\hline Technique 1 & Evaluated area $\left(\mathrm{ft}^{2}\right)$ & 1190.00 & 282.00 & 188.00 & 132.00 \\
& Defective area $\left(\mathrm{ft}^{2}\right)$ & 8.00 & 5.00 & 3.00 & 2.00 \\
& Defective area as a percentage & 0.67 & 1.77 & 1.59 & 1.52 \\
\hline & Average & 554.00 & 430.00 & 228.00 & 190.00 \\
\hline Technique III & Evaluated area $\left(\mathrm{ft}^{2}\right)$ & 13.5 & 7.00 & 8.00 & 4.50 \\
& Defective area $\left(\mathrm{ft}^{2}\right)$ & 2.43 & 1.63 & 3.51 & 2.37 \\
& Defective area as a percentage & \multicolumn{5}{|c|}{$2.49 \%$} & \\
\hline & Average & 140.00 & 120.00 & 179.00 & 225.00 \\
\hline \multirow{2}{*}{ Technique III } & Evaluated area $\left(\mathrm{ft}^{2}\right)$ & 2.25 & 0 & 2.25 & 3.00 \\
& Defective area $\left(\mathrm{ft}^{2}\right)$. & 1.61 & 0 & 1.26 & 1.33 \\
& Defective area as a percentage & 0 & \multicolumn{5}{|c|}{$1.05 \%$} & \\
\hline
\end{tabular}

of the bed is used to correct any level differences due to an improperly laid concrete bed. Secondly, when two adjoining tiles are fixed on to mortar beds formed with mortar coming from twc batches of which the percentage of water used is different making them divergent in compressibility. However, these problems could be significantly minimised by engaging tilers who either have been trained or have acquired necessary skills, through experience applying this technique.

\section{Conclusions}

According to the results obtained, Technique III is found to be the most economical of all the techniques mainly due to less use of cement and sand with Technique I and Technique II taking second and third positions respectively. Also, Technique III represents the lowest average for the defective area caused due to poor bonding while Technique II shows the most adverse results. However, with respect to defective area caused due to level difference, Technique III performs poorly while results pertaining to Technique I indicates that it is a much improved technique in this respect. It was also observed that Technique III performs better when the thickness of the mortar bed laid is relatively small. This means that if the concrete bed can be laid with a minimum level difference, requiring a thinner mortar bed, results of this technique can be enhanced. Currently, the skill level of the tilers who used this technique fall quite short of what is required. Since this technique consumes less cement and sand it becomes not only an environmentally friendly method but also contributes towards the national economy by conserving energy and saving foreign exchange.

Unlike the other two techniques, in this the tiles are laid over a wet mortar bed and therefore the tiller does not get enough assistance from the bed to align the tile, with respect to other tiles in $\mathrm{X}, \mathrm{Y}$ and $\mathrm{Z}$ directions even after their careful positioning. As such, the level of skill required of a tiller adopting this technique is considerably high.

One issue with this technique is that the tiller cannot.walk on tiles until a considerable time has elapsed since the wet mortar bed beneath needs a longer time for stiffening. Accordingly, the mortar bed should be laid on a relatively small area which depends on the maximum reach of the tiller for laying and cleaning. 
Table 5.3.3:Average Percentage of Defective Area Due to Level Difference

\begin{tabular}{|c|c|c|c|c|c|}
\hline & & Site I & Site II & Site III & Site IV \\
\hline \multirow[t]{4}{*}{ Technique I } & Evaluated area $\left(\mathrm{ft}^{2}\right)$ & 1190.00 & 282.00 & 188.00 & 132.00 \\
\hline & Defective area $\left(\mathrm{ft}^{2}\right)$ & 28.00 & 6.00 & 4.00 & 3.50 \\
\hline & Defective area as a percentage & 2.35 & 2.12 & 2.12 & 2.65 \\
\hline & Average & \multicolumn{4}{|c|}{$2.31 \%$} \\
\hline \multirow[t]{4}{*}{ Technique II } & Evaluated area $\left(\mathrm{ft}^{2}\right)$ & 554.00 & 430.00 & 228.00 & 190.00 \\
\hline & Defective area $\left(\mathrm{ft}^{2}\right)$ & 18.00 & 14.00 & 9.00 & 5.00 \\
\hline & Defective area as a percentage & 3.24 & 03.25 & 3.94 & 2.63 \\
\hline & Average & \multicolumn{4}{|c|}{$3.26 \%$} \\
\hline \multirow[t]{4}{*}{ Technique III } & Evaluated area $\left(\mathrm{ft}^{2}\right)$ & 140.00 & 120.00 & 179.00 & 225.00 \\
\hline & Defective area $\left(\mathrm{ft}^{2}\right)$ & 6.00 & 4.00 & 7.00 & 8.00 \\
\hline & Defective area as a percentage & 4.29 & 3.33 & 3.91 & 3.50 \\
\hline & Average & \multicolumn{4}{|c|}{$3.75 \%$} \\
\hline
\end{tabular}

Therefore, the tiller must pre-decide on the width of the mortar bed before he sets out to lay the mortar bed so that he does not have to walk on wet tiles in pursuing his work.

\section{Recommendations}

The adoption of this technique is bound to bring down the overall cost of tiling and will be preferred to other alternative flooring methods thereby increasing the demand for ceramic tiles. Tile manufactures and importers can gain from this situation and so they should take steps to promote this method among the stakeholders. This technique, when adopted on a mass scale can contribute towards the national economy by saving foreign exchange and conserving energy. Therefore, state sector institutions engaged in promoting the construction industry, vocational training and technical education should endeavour to promote this technique by training personnel engaged in tiling. The benefits of this technique can be further improved if the tilers can be trained to apply this. Such training can not only increase the productivity but also minimise the extent of defective area caused due to divergent levels of individual tiles.

\section{Bibliography}

1. Cares and Wines, The art of Tile setting, Chas and Benet Publishers, London, 1954

2. Floor and Wall Tiling, Department of Labour and National services, Australia, 1995

\section{Biographical Sketch:}

D. A. R. DOLAGE, obtained his degree in BSc. Engineering, specialising in Civil Engineering, from the University of Moratuwa in 1986. Thereafter, in 1991 he obtained an MSc in Construction Management from the University of Reading, UK. Subsequently, he also obtained an MA in Economics from the University of Colombo and an MBA from Sri Jayewardenapura University in 1998 and 2000 respectively. He is a Senior Lecturer attached to the Department of Civil Engineering, Open University of Sri Lanka and currently serves as the Head of the Department. He is also a Fellow of the Institution of Engineers, Sri Lanka. 